\title{
Vaccines and immunotherapy against fungi: the new frontier
}

\section{Joshua D. Nosanchuk ${ }^{1,2 *}$ and Carlos P. Taborda ${ }^{3}$}

1 Department of Medicine, Albert Einstein College of Medicine, Bronx, NY, USA

2 Department of Microbiology and Immunology, Albert Einstein College of Medicine, Bronx, NY, USA

${ }^{3}$ Laboratory of Medical Mycology-LIM53/IMTSP, Department of Microbiology, Institute of Biomedical Sciences, University of São Paulo, São Paulo, Brazil

${ }^{*}$ Correspondence: josh.nosanchuk@einstein.yu.edu

Edited by:

Axel A. Brakhage, Friedrich Schiller University Jena, Germany

Reviewed by:

Axel A. Brakhage, Friedrich Schiller University Jena, Germany

Invasive fungal diseases have increased many fold over the past 50 years. Current treatment regimens typically require prolonged administration of antifungal medications that can have significant toxicity. Moreover, our present potent antifungal armamentarium fails to eradicate fungal pathogens from certain compromised hosts. Additionally, invasive fungal diseases continue to have unacceptably high mortality rates. A growing body of work has focused on the utility of vaccines and/or immunotherapy as a powerful tool in combating mycoses, either for the active treatment, as an adjuvant, or in the prevention of specific fungal pathogens. This Research Topic "Vaccines and Immunotherapy against fungi: a new frontier" in Frontiers in Fungi and their Interactions details the exciting progress in developing vaccines and immunotherapy for fungi.

The critical requirement for understanding the degrees of engagement of host defense pathways in responding to fungal invasion has led to an increased focus on host-pathogen interactions. In this Research Topic, Carvalho et al. (2012) review our current progress on this endeavor and underscore the need for coordinated cross-disciplinary future efforts. A major focus of the special Topic is the advance of vaccine strategies against major fungal pathogens. To this extent, the issue focuses on developments in vaccine strategies against Candida albicans (Vecchiarelli et al., 2012), Aspergillus fumigatus (Diaz-Arevalo et al., 2012), Cryptococcus neoformans (Hole and Wormley, 2012), and Paracoccidioides brasiliensis (Travassos and Taborda, 2012). Progress in optimizing adjuvants for a vaccine against P. brasiliensis is also presented (Mayorga et al., 2012). Shifting host responses to facilitate fungal clearance is shown in work utilizing ArtinM, a D-mannose binding lectin from Artocarpus heterophyllus, which modulates immunity against $P$. brasiliensis (Ruas et al., 2012). Along this line, information is presented regarding the immunomodulatory effects of fungal immunogens and how they impact disease (Rodrigues and Nimrichter, 2012). The utility of antibody based therapeutic approaches is presented against a specific fungus, Histoplasma capsulatum (Nosanchuk et al., 2012), and as a broad-spectrum therapeutic using antibody labeled with fungicidal nuclides (Nosanchuk and Dadachova, 2012). A therapeutic monoclonal antibody in early phase research for sporotrichosis is also detailed (Almeida, 2012). Moreover, the broad potential of antibody-derived "killer peptides" is presented (Magliani et al., 2012). Finally, new information about the antifungal activity of "old" drugs is discussed. Hydroxyurea is shown to impact the sphingolipid pathway underscoring the role of these compounds in fungal biology (Tripathi et al., 2012). The diverse activities of Amphotericin B on both fungi, impacting ergosterol stability and cellular morphology, and host cells, engaging pattern receptors, is critically summarized (Mesa-Arango et al., 2012).

In sum, these articles broadly paint the current spectrum of investigations on host-pathogen interactions and provide a review of the state-of-the-art in vaccinology and immunotherapy against fungi. The information presented also underscores the rich areas for future study, all promising improved therapeutics against fungal invaders.

\section{ACKNOWLEDGMENTS}

The authors sincerely acknowledge the efforts of all of the authors who contributed to this Research Topic. Joshua D. Nosanchuk is supported in part by NIH grant AI52733 and an Irma T. Hirschl/Monique Weill-Caulier Trust Research Award. Carlos P. Taborda is supported by grants 07/58750-0, 2011/17267-4 from Fundação de Amparo à Pesquisa do Estado de São Paulo (FAPESP) and Conselho Nacional de Desenvolvimento Científico e Tecnológico (CNPq).

\section{REFERENCES}

Almeida, S. (2012). Therapeutic monoclonal antibody for Sporotrichosis. Front. Microbio. 3:409. doi: 10.3389/ fmicb.2012.00409

Carvalho, A., Cunha, C., Iannitti, R. G., Casagrande, A., Bistoni, F., Aversa, F., et al. (2012). Host defense pathways against fungi: the basis for vaccines and immunotherapy. Front. Microbio. 3:176. doi: 10.3389/ fmicb.2012.00176

Diaz-Arevalo, D., Ito, J. I., and Kalkum, M. (2012). Protective effector cells of the recombinant Asp f3 anti-aspergillosis vaccine. Front. Microbio. 3:299. doi: 10.3389/fmicb. 2012.00299
Hole, C. R., and Wormley, F. L. Jr. (2012). Vaccine and immunotherapeutic approaches for the prevention of cryptococcosis: lessons learned from animal models. Front. Microbio. 3:291. doi: 10 3389/fmicb.2012.00291

Magliani, W., Conti, S., Giovati, L., Zanello, P. P., Sperindè,
M., Ciociola, T., et al. (2012). Antibody peptide based antifungal immunotherapy. Front. Microbio. 3:190. doi: 10.3389/fmicb.2012. 00190

Mayorga, O., Muñoz, J. E., Lincopan, N., Teixeira, A. F., Ferreira, L. C. S., Travassos, L. R., et al. (2012). The role of adjuvants in therapeutic 
protection against paracoccidioidomycosis after immunization with the P10 peptide. Front. Microbio. 3:154. doi: 10.3389/fmicb. 2012.00154

Mesa-Arango, A. C., Scorzoni, L., and Zaragoza, O. (2012). It only takes one to do many jobs: amphotericin $\mathrm{B}$ as antifungal and immunomodulatory drug. Front. Microbio. 3:286. doi: 10.3389/fmicb.2012. 00286

Nosanchuk, J. D., and Dadachova, E. (2012). Radioimmunotherapy of fungal diseases: the therapeutic potential of cytocidal radiation delivered by antibody targeting fungal cell surface antigens. Front. Microbio. 2:283. doi: 10.3389/fmicb. 2011.00283
Nosanchuk, J. D., Zancopé-Oliveira, R. M., Hamilton, A. J., and Guimarães, A. J. (2012). Antibody therapy for histoplasmosis. Front. Microbio. 3:21. doi: 10.3389/fmicb.2012 00021

Rodrigues, M. L., and Nimrichter, L. (2012). In good company: association between fungal glycans generates molecular complexes with unique functions. Front. Microbio. 3:249. doi: 10.3389/fmicb.2012. 00249

Ruas, L. P., Carvalho, F. C., and Roque-Barreira, M.-C. (2012). ArtinM offers new perspectives in the development of antifungal therapy. Front. Microbio. 3:218. doi: 10.3389/fmicb.2012. 00218
Travassos, L. R., and Taborda, C. P. (2012). New advances in the development of a vaccine against paracoccidioidomycosis. Front. Microbio. 3:212. doi: 10.3389/fmicb. 2012.00212

Tripathi, K., Mor, V., Bairwa, N. K., Del Poeta, M., and Mohanty, B. K. (2012). Hydroxyurea treatment inhibits proliferation of Cryptococcus neoformans in mice. Front. Microbio. 3:187. doi: 10.3389/ fmicb.2012.00187

Vecchiarelli, A., Pericolini, E., Gabrielli, E., and Pietrella, D. (2012). New approaches in the development of a vaccine for mucosal candidiasis: progress and challenges. Front. Microbio. 3:294. doi: 10.3389/fmicb. 2012.00294
Received: 22 November 2012; accepted: 06 January 2013; published online: 25 January 2013.

Citation: Nosanchuk JD and Taborda CP (2013) Vaccines and immunotherapy against fungi: the new frontier. Front. Microbio. 4:6. doi: 10.3389/fmicb. 2013.00006

This article was submitted to Frontiers in Fungi and Their Interactions, a specialty of Frontiers in Microbiology.

Copyright (c) 2013 Nosanchuk and Taborda. This is an open-access article distributed under the terms of the Creative Commons Attribution License, which permits use, distribution and reproduction in other forums, provided the original authors and source are credited and subject to any copyright notices concerning any third-party graphics etc. 